\title{
Mature Defense Mechanisms Affect Successful Adjustment in Young Adulthood-Adjustment to Military Service in South Korea
}

\author{
Ji-Won Nam¹, Jee Hyun $\mathrm{Ha}^{1}{ }^{\bowtie}$, Eunkyung $\mathrm{Choi}^{2}$, Doo-Heum Park${ }^{1}$, and Seung-Ho Ryu ${ }^{1}$ \\ ${ }^{1}$ Department of Psychiatry, Konkuk University School of Medicine, Seoul, Republic of Korea \\ ${ }^{2}$ Korea Workers' Compensation and Welfare Service, Incheon Hospital, Incheon, Republic of Korea
}

\begin{abstract}
Objective A defense mechanism is an automatic psychological process necessary for successful adaptation. It reflects adaptive capacity. The purpose of this study is to explore the relationship between the adaptation ability of individuals who face mandatory military service and the pattern of defense mechanisms.

Methods The subjects were 69 men $(21.4 \pm 2.2$ years) who expressed psychological difficulties in three military service situations. Control group was 36 men ( $24.0 \pm 1.4$ years) who had successfully completed military service. We examined psychiatric history, the pattern of defense mechanisms, and depression and anxiety levels. Defense mechanisms were compared between two groups.

Results The maladjusted group used immature defenses more frequently than the control group did. There were no differences in the defense patterns according to diagnosis. The control group used more identification and rationalization, classified as immature defenses. The temporarily maladjusted group used more somatization, regression, and avoidance.

Conclusion Using mature defense mechanisms helped young adults to adapt to a particular situation. The maturity of the defense is more valuable than the psychiatric diagnosis. Some immature defenses are also helpful to adapt. We cautiously assume that some defenses can be protective or risk factors in adapting to stressful situations by young adults.

Psychiatry Investig 2019;16(7):484-490
\end{abstract}

Key Words Young adulthood, Social adjustment, Military personnel, Defense mechanism.

\section{INTRODUCTION}

A defense mechanism is an automatic psychological process that protects an individual from anxiety and from internal or external risks or stressors. ${ }^{1}$ Defense mechanisms work largely in unconscious states and are associated with emotional conflicts and responses to internal and external stress. It is necessary for successful adaptation to the environment or for coping with stress. As Freud first introduced the concept of 'defense', it was based on the theory of psychoanalysis. Initially, he thought that psychiatric disorders were associated with specific defenses. ${ }^{2}$ Anna Freud then used the term 'de-

Received: July 9, 2018 Revised: September 23, 2018

Accepted: November 7, 2018

$\triangle$ Correspondence: Jee Hyun Ha, MD, PhD

Department of Psychiatry, School of Medicine, Konkuk University, 120-1

Neungdong-ro, Gwangjin-gu, Seoul 05029, Republic of Korea

Tel: +82-2-2030-7569, Fax: +82-2-2030-7748, E-mail: jhnha@kuh.ac.kr

(c) This is an Open Access article distributed under the terms of the Creative Commons Attribution Non-Commercial License (https://creativecommons.org/licenses/bync/4.0) which permits unrestricted non-commercial use, distribution, and reproduction in any medium, provided the original work is properly cited. fense' and presented a list of defenses for the first time. She suggested that a defense system developed according to the maturity of the ego. ${ }^{3}$ Gradually, as the concept evolved, defense was viewed as a general function of the ego, not only the pathological, but also the general adaptation. Finally, a person's defensive mechanism reflects personality traits, emotional maturity, and adaptive abilities. If one fails to mobilize the defense mechanisms successfully, psychopathology could occur. There was an effort to classify defense mechanisms according to psychological maturity or adaptability. Through a 30-year follow up of 95 university students, Vaillant identified four types of defense mechanisms and associations between the maturity of defense mechanisms and psychological maturation. Maturity of defense mechanisms has a positive association with adaptability and a negative association with psychopathology. ${ }^{4,5}$ As a result, a Defense Functioning Scale, which classified defenses into seven categories, was included in the DSM-IV. ${ }^{1}$ Bonds listed the defense mechanism as a phase of maladjustment to adjustment according to maturity. ${ }^{6}$ Defense mechanism plays an important role in the success or 
failure of personal adaptation to the environment. Based on the previous findings, researchers wanted to see the patterns of defense mechanisms that affect the success or failure of adaptation to environment in the subjects of similar age groups under the same particular stress conditions. We chose military service as a specific stress situation for the young adult male population. According to the Military Service Act of South Korea, every male must serve in the military for a specific period of time, approximately two years. Military culture has been characterized by strict discipline, hierarchical order, closure, and restriction of individual freedom and autonomy, Some of the soldiers have failed to adapt to this particular society. ${ }^{7}$ In South Korea, every male will be screened to find out his military service capacity for the first time at 18 years of age, and most of them complete their military service obligations in their early 20s. This period is also the entry period of adulthood from adolescence, and they have fewer social experiences and stressful situations. Therefore, military service often acts as the first big life stress, and there may likely be difficulty in adaptation. Enrollment screenings are done in three stages. The first screening is done by the Military Manpower Administration (MMA) at age 18. The second screening is conducted at a training camp, and the third evaluation is conducted after assignment to a military unit.

Despite this step-by-step system, the number of maladjusted personnel is increasing. The number of patients in psychiatric clinics in the Korean Armed Forces Capital Hospital increased by $49.2 \%$, from 6,278 in 2010 to 9,381 in $2014 .^{7}$ It is estimated that about $20 \%$ of soldiers were troubled by military service in $2014,{ }^{8}$ perhaps because the Korean military system is not voluntary but is based on conscription. In this respect, screening to predict maladjustment to military service is important. Until now, factors predicting military maladjustment have been life stress, temperament, resilience, intellectual ability, and the presence of mental illness. ${ }^{9-11}$ However, except for low intelligence or psychosis, there is no clear predictor of military service maladjustment, ${ }^{9}$ probably because it is not easy to predict the adaptability of young adults. In modern society, more people are complaining about subclinical psychological difficulties, which are difficult to diagnose clearly. Therefore, we tried to evaluate the adaptive capacity by evaluating the defense mechanisms rather than the existence of mental illness. The purpose of this study is to evaluate the patterns and maturity of defense mechanisms and to find out whether mature defensive patterns are related to adaptation to stressors, such as mandatory military service, among young adult males.

\section{METHODS}

\section{Participants}

A maladjusted group was selected from among those who had a full psychiatric evaluation in the department of Konkuk University Medical Center from September 2005 to February 2014. The total number of enrolled subjects was 69 (mean age 21.4 \pm 2.2 ); all were male. Enrolled subjects were recruited by three routes. First, patients under treatment for preexisting mental illness were referred for a medical certificate to be submitted to the MMA, or a psychiatric examination as recommended by a physical examination of the MMA (Group 1, $\mathrm{n}=28$ ). Second, in a training camp, those for whom mental illness was suspected or displayed sudden anxiety and emotional instability (Group 2, n=27). Third, some who, after being deployed to the unit, had various mental problems, about which a private hospital was consulted (Group 3, n=14). We retrospectively analyzed the medical records and psychological test results, and obtained demographic data such as gender, age, and the date of military service, as well as on the EWHA defense system, Beck Depression Inventory, and State-Trait Anxiety Inventory. In addition, the final psychiatric diagnosis was confirmed by a medical certificate. Psychiatric evaluation was done by certified psychiatrists and by a full battery of psychological tests, including an IQ test, Rorschach test, and various self-report questionnaires. According to the psychiatric diagnosis, enrolled subjects was divided into three groups (A, adjustment disorder or post-traumatic stress disorder, $\mathrm{n}=14$; $\mathrm{B}$, depression or anxiety disorders, $\mathrm{n}=28$; $\mathrm{C}$, psychosis, including schizophrenia, bipolar disorders, and mental retardation, $\mathrm{n}=15$ ). Subjects whose final diagnosis was normal were classified as a temporarily maladjusted group $(n=12)$.

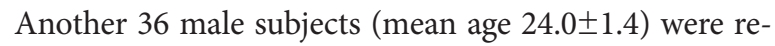
cruited as a control group who met the following criteria: 1 ) 21 to 30 years of age, 2) had completed their military services within two preceding years, and 3) had no history of psychiatric illness. Most military services need moderate degree of stress and required staying in camp during service period. We assumed that completing the military service would reflect the successful adjustment. Self-report questionnaires were used to obtain demographic data and to evaluate defense mechanism/anxiety/depression. Psychiatrists conducted interviews to investigate the history of psychiatric and other physical disorders. Patients with psychiatric disorders or other physical disorders were excluded from the study, as were those with a score of more than 10 on the Beck Depression Inventory or a score over 52/54 on the State-Trait Anxiety Inventory. Informed consent was obtained before the research was conducted. They each received a gratuity $(10,000$ won, =about \$9) after completing the interview and survey. 
The anonymity of the subject was guaranteed, and the study was approved by the Institutional Review Board of Konkuk University Medical Center (KUH1050077).

\section{Measures}

\section{Ewha Defense Mechanisms Test (EDMT)}

We used the EDMT to measure defense mechanism of subjects. Based on the Korean traditional proverbs, developers derived specific items and evaluated the defensive measures reflecting cultural characteristics and contexts. The test consisted of 20 defense mechanism measurements, and every scale included 10 questions, for a grand total of 200 questions. The 5-point Likert Scale was used to calculate the scores, and the aggregate from all 10 questions made up the raw score. The revised score was applied afterward. ${ }^{12,13}$

\section{Classification of defenses adapted from Vailliant}

Mature defenses: altruism, anticipation, humor, sublimation, suppression

Neurotic defenses: reaction formation, displacement, controlling, rationalization, dissociation

Immature defenses: bragging, identification, passive-aggressive, somatization, acting out, regression, evasion

Narcissistic-Psychotic defenses: projection, denial, distortion

\section{The Beck Depression Inventory (BDI)}

It is a self-reported questionnaire used to assess the presence and severity of depressive symptoms. ${ }^{14} \mathrm{BDI}$ has good reliability and validity. It consists of 21 items with 4 Likert scales. The total range of scores is from 0 to 63 . It has been translated and standardized in Korean. ${ }^{15}$

The State-Trait Anxiety Inventory (STAI)

It is a 20-item instrument designed to measure state and trait

Table 1. Comparison of the results of EDMT, BDI, STAI-S, and STAI-T scales between Group 1 and Group 2

\begin{tabular}{|c|c|c|c|c|c|}
\hline \multirow{3}{*}{ Scale } & \multicolumn{4}{|c|}{ Group } & \multirow{3}{*}{$\mathrm{p}$} \\
\hline & \multicolumn{2}{|c|}{ Control group $(\mathrm{N}=36)$} & \multicolumn{2}{|c|}{ Maladjusted group $(\mathrm{N}=69)$} & \\
\hline & Mean & $\mathrm{SD}$ & Mean & SD & \\
\hline \multicolumn{6}{|l|}{ EDMT } \\
\hline Bragging & 5.86 & 1.62 & 6.01 & 2.23 & 0.716 \\
\hline Reaction formation & 5.19 & 2.32 & 4.77 & 2.56 & 0.404 \\
\hline Identification* & 5.92 & 2.01 & 4.80 & 2.29 & 0.015 \\
\hline Passive aggressive* & 4.67 & 1.96 & 5.81 & 2.65 & 0.024 \\
\hline Projection* & 4.83 & 2.15 & 6.16 & 2.71 & 0.012 \\
\hline Displacement* & 4.11 & 2.11 & 5.48 & 2.70 & 0.009 \\
\hline Denial & 4.72 & 1.77 & 5.06 & 2.06 & 0.407 \\
\hline Controlling* & 5.42 & 1.98 & 4.04 & 2.35 & 0.003 \\
\hline Suppression** & 5.69 & 1.8 & 4.12 & 2.06 & 0.000 \\
\hline Distortion* & 4.78 & 1.90 & 3.68 & 2.00 & 0.008 \\
\hline Anticipation** & 6.39 & 1.76 & 4.45 & 2.34 & 0.000 \\
\hline Rationalization* & 5.50 & 1.40 & 4.57 & 2.28 & 0.027 \\
\hline Dissociation** & 4.17 & 1.56 & 6.04 & 2.88 & 0.000 \\
\hline Somatization** & 4.19 & 2.23 & 6.88 & 2.59 & 0.000 \\
\hline Sublimation** & 5.14 & 1.99 & 3.61 & 1.83 & 0.000 \\
\hline Acting out* & 3.89 & 1.80 & 5.70 & 2.74 & 0.001 \\
\hline Altruism & 4.36 & 2.30 & 3.55 & 2.29 & 0.089 \\
\hline Regression* & 4.78 & 2.52 & 6.25 & 2.77 & $0.00 s$ \\
\hline Humor** & 5.25 & 1.57 & 3.46 & 2.18 & 0.000 \\
\hline Evasion* & 5.06 & 2.06 & 6.41 & 2.53 & 0.007 \\
\hline $\mathrm{BDI}^{* *}$ & 5.81 & 4.93 & 22.23 & 15.44 & 0.000 \\
\hline STAI-S** & 37.81 & 8.14 & 55.94 & 14.08 & 0.000 \\
\hline STAI-T** & 39.19 & 8.67 & 54.58 & 13.73 & 0.000 \\
\hline
\end{tabular}

${ }^{*} \mathrm{p}<0.05,{ }^{* *} \mathrm{p}<0.001$. EDMT: Ewha Defense Mechanism Test, BDI: Beck Depression Inventory, STAI: State-Trait Anxiety Inventory 
anxiety in normal person. We administered the Korean version of the STAI in this study. ${ }^{16}$

\section{Statistical analysis}

A Student $\mathrm{t}$ test was performed between the maladjusted group and the control group. The maladjusted group was divided into three groups based on the process of military enrollment (Groups 1, 2, 3) and ANOVA was performed. A Scheffe test was done for post hoc analysis. We divided the maladjusted group by their psychiatric diagnosis into three groups and compared their defense mechanism patterns by using non-parametric analysis with Kruskal-Wallis analysis. Finally, the defense mechanism patterns of the temporarily maladjusted group were compared with those of the control group by using independent sample t-tests. All analyses were performed using SPSS for Windows (SPSS Windows 17.0, SPSS, Inc, Chicago, IL, USA), with the level of statistical significance set at $\mathrm{p}<0.05$.

\section{RESULTS}

Depressive symptoms and anxiety symptoms were higher

Table 2. Comparison of the results of the EDMT, BDI, and STAI scales before and after enrollment in a military camp

\begin{tabular}{|c|c|c|c|c|c|c|c|c|c|c|}
\hline \multirow{2}{*}{ Scales } & \multicolumn{2}{|c|}{ Control $(\mathrm{N}=36)^{\mathrm{a}}$} & \multicolumn{2}{|c|}{ Pre_enlist $(\mathrm{N}=29)^{\mathrm{b}}$} & \multicolumn{2}{|c|}{ Post_enlist $(\mathrm{N}=40)^{\mathrm{c}}$} & \multicolumn{2}{|c|}{ ANOVA } & \multicolumn{2}{|c|}{ Post-hoc (scheffe test) } \\
\hline & Mean & $\mathrm{SD}$ & Mean & SD & Mean & SD & $\mathrm{F}$ & $\mathrm{p}$ & & $\mathrm{p}$ \\
\hline \multicolumn{11}{|l|}{$\overline{\mathrm{EDMT}}$} \\
\hline Bragging & 5.86 & 1.62 & 5.76 & 2.01 & 6.20 & 2.39 & 0.457 & 0.635 & ns & \\
\hline Reaction formation & 5.19 & 2.32 & 4.24 & 2.37 & 5.15 & 2.65 & 1.500 & 0.228 & ns & \\
\hline Identification & 5.92 & 2.01 & 4.79 & 2.18 & 4.80 & 2.39 & 3.050 & 0.052 & ns & \\
\hline Passive aggressive* & 4.67 & 1.96 & 5.31 & 2.59 & 6.18 & 2.66 & 3.717 & 0.028 & $\mathrm{a}<\mathrm{c}$ & 0.029 \\
\hline Projection* & 4.83 & 2.15 & 5.76 & 2.98 & 6.45 & 2.49 & 3.881 & 0.024 & $a<c$ & 0.024 \\
\hline Displacement* & 4.11 & 2.11 & 5.28 & 2.95 & 5.63 & 2.53 & 3.637 & 0.030 & $\mathrm{a}<\mathrm{c}$ & 0.037 \\
\hline Denial & 4.72 & 1.77 & 5.17 & 2.24 & 4.98 & 1.94 & 0.427 & 0.653 & ns & \\
\hline Controlling* & 5.42 & 1.98 & 4.38 & 2.40 & 3.80 & 2.32 & 5.045 & 0.008 & $a>c$ & 0.009 \\
\hline Suppression* & 5.69 & 1.80 & 4.14 & 2.10 & 4.10 & 2.05 & 7.506 & 0.001 & $a>b, a>c$ & $\begin{array}{l}0.009 \\
0.003\end{array}$ \\
\hline Distortion* & 4.78 & 1.90 & 4.10 & 2.01 & 3.38 & 1.97 & 4.883 & 0.009 & $a>c$ & 0.010 \\
\hline Anticipation* & 6.39 & 1.76 & 5.34 & 2.44 & 3.80 & 2.07 & 14.915 & 0.000 & $a>c, b>c$ & $\begin{array}{l}0.000 \\
0.012\end{array}$ \\
\hline Rationalization & 5.50 & 1.40 & 4.83 & 2.49 & 4.38 & 2.12 & 2.939 & 0.057 & ns & \\
\hline Dissociation* & 4.17 & 1.56 & 5.93 & 3.16 & 6.13 & 2.70 & 6.596 & 0.002 & $\mathrm{a}<\mathrm{b}, \mathrm{a}<\mathrm{c}$ & $\begin{array}{l}0.023 \\
0.004\end{array}$ \\
\hline Somatization* & 4.19 & 2.23 & 6.55 & 2.96 & 7.13 & 2.29 & 14.458 & 0.000 & $\mathrm{a}<\mathrm{b}, \mathrm{a}<\mathrm{c}$ & $\begin{array}{l}0.001 \\
0.000\end{array}$ \\
\hline Sublimation* & 5.14 & 1.99 & 3.86 & 1.64 & 3.43 & 1.96 & 8.222 & 0.000 & $a>b, a>c$ & $\begin{array}{l}0.029 \\
0.001\end{array}$ \\
\hline Acting out* & 3.89 & 1.80 & 5.17 & 2.75 & 6.08 & 2.70 & 7.621 & 0.001 & $\mathrm{a}<\mathrm{c}$ & 0.001 \\
\hline Altruism & 4.36 & 2.30 & 3.90 & 2.35 & 3.30 & 2.24 & 2.050 & 0.134 & ns & \\
\hline Regression* & 4.78 & 2.52 & 5.83 & 3.00 & 6.55 & 2.59 & 4.142 & 0.019 & $\mathrm{a}<\mathrm{c}$ & 0.019 \\
\hline Humor* & 5.25 & 1.57 & 3.17 & 1.89 & 3.68 & 2.37 & 10.023 & 0.000 & $\mathrm{a}>\mathrm{b}, \mathrm{a}>\mathrm{c}$ & $\begin{array}{l}0.000 \\
0.004\end{array}$ \\
\hline Evasion* & 5.06 & 2.06 & 5.69 & 2.73 & 6.93 & 2.28 & 6.277 & 0.003 & $a<c$ & 0.003 \\
\hline BDI* & 5.81 & 4.93 & 20.69 & 16.59 & 23.35 & 14.66 & 19.582 & 0.000 & $\mathrm{a}<\mathrm{b}, \mathrm{a}<\mathrm{c}$ & $\begin{array}{l}0.000 \\
0.000\end{array}$ \\
\hline STAI-S* & 37.81 & 8.14 & 54.72 & 15.00 & 56.83 & 13.50 & 25.475 & 0.000 & $\mathrm{a}<\mathrm{b}, \mathrm{a}<\mathrm{c}$ & $\begin{array}{l}0.000 \\
0.000\end{array}$ \\
\hline STAI-T* & 39.19 & 8.67 & 53.00 & 14.77 & 55.73 & 13.00 & 19.040 & 0.000 & $\mathrm{a}<\mathrm{b} a<\mathrm{c}$ & $\begin{array}{l}0.000 \\
0.000\end{array}$ \\
\hline
\end{tabular}

${ }^{*} \mathrm{p}<0.05$. EDMT: Ewha Defense Mechanism Test, BDI: Beck Depression Inventory, STAI: State-Trait Anxiety Inventory, Pre_enlist: Evaluation was done before enlistment (Group 1), Post_enlist: Evaluation was done after enlistment (Group 2 \& 3) 
in the maladjusted group than in the control group (BDI 22.23 \pm 15.44 vs. $5.81 \pm 4.93$, STAI-S $55.94 \pm 14.08$ vs. $37.81 \pm 8.14$, STAI-T $54.58 \pm 13.73$ vs. $39.19 \pm 8.67)$. Some of the subjects were diagnosed as depressive disorders or anxiety disorders. Except these subjects, most of maladjusted group showed relatively higher level of depressive symptoms and anxiety symptoms. It implied that they have been experiencing modest level of psychological difficulties in front of military services.

Of the defense mechanisms, passive-aggression, projection, displacement, dissociation, somatization, acting out, regression, and evasion were frequently used in the maladjusted group. In contrast, identification, controlling, suppression, distortion, anticipation, rationalization, sublimation, and humor were less frequently used (Table 1 ).

The subjects were divided into two groups: those who were evaluated before enlistment (Gr 1) and those who were evaluated after enlistment (Gr 2 \& 3 ) and compared with the con- trol group. There was no difference in bragging, reaction formation, identification, denial, rationalization, and altruism between the three groups. Post-enlistment subjects (Gr 2 \& 3) used passive-aggression, projection, displacement, acting out, regression, and evasion more frequently than the control group did. Post-enlistment subjects (Gr 2 \& 3) used anticipation less frequently than did the control group or pre-enlistment subjects (Gr 1). The control group more frequently used suppression, sublimation and humor, and less frequently used dissociation and somatization than did either Grlor Gr 2 \& 3 (Table 2).

According to the psychiatric diagnosis, enrolled subjects were divided into three groups. There was no difference in using defense mechanisms compared with the finally normal subjects (the control group and the temporarily maladjusted group). Temporary maladjusted group more frequently used somatization, regression and evasion, and less frequently used controlling, suppression, anticipation, and humor than

Table 3. Comparison of the results of EDMT, BDI, and STAI scales between temporarily maladjusted subjects and the control group

\begin{tabular}{|c|c|c|c|c|c|}
\hline \multirow{3}{*}{ Scale } & \multicolumn{4}{|c|}{ Group } & \multirow{3}{*}{$\mathrm{p}$} \\
\hline & \multicolumn{2}{|c|}{ Control $(\mathrm{N}=36)$} & \multicolumn{2}{|c|}{ Normal $(\mathrm{N}=12)$} & \\
\hline & Mean & $\mathrm{SD}$ & Mean & $\mathrm{SD}$ & \\
\hline \multicolumn{6}{|l|}{ EDMT } \\
\hline Bragging & 5.86 & 1.62 & 6.42 & 1.73 & 0.389 \\
\hline Reaction formation & 5.19 & 2.32 & 4.50 & 2.20 & 0.348 \\
\hline Identification & 5.92 & 2.01 & 5.08 & 2.71 & 0.571 \\
\hline Passive aggressive & 4.67 & 1.96 & 5.33 & 3.20 & 1.000 \\
\hline Projection & 4.83 & 2.15 & 5.67 & 2.93 & 0.397 \\
\hline Displacement & 4.11 & 2.11 & 5.17 & 2.76 & 0.198 \\
\hline Denial & 4.72 & 1.77 & 4.83 & 1.99 & 0.904 \\
\hline Controlling* & 5.42 & 1.98 & 3.58 & 1.83 & 0.007 \\
\hline Suppression* & 5.69 & 1.80 & 3.67 & 1.50 & 0.002 \\
\hline Distortion & 4.78 & 1.90 & 4.33 & 1.67 & 0.439 \\
\hline Anticipation* & 6.39 & 1.76 & 3.92 & 1.88 & 0.001 \\
\hline Rationalization & 5.50 & 1.40 & 4.25 & 2.30 & 0.085 \\
\hline Dissociation & 4.17 & 1.56 & 5.50 & 2.91 & 0.192 \\
\hline Somatization* & 4.19 & 2.23 & 6.25 & 2.56 & 0.014 \\
\hline Sublimation & 5.14 & 1.99 & 3.83 & 2.29 & 0.102 \\
\hline Acting out & 3.89 & 1.80 & 4.33 & 2.57 & 0.826 \\
\hline Altruism & 4.36 & 2.30 & 4.08 & 2.19 & 0.699 \\
\hline Regression* & 4.78 & 2.52 & 6.92 & 3.26 & 0.032 \\
\hline Humor** & 5.25 & 1.57 & 2.33 & 1.37 & 0.000 \\
\hline Evasion* & 5.06 & 2.06 & 6.75 & 2.30 & 0.026 \\
\hline BDI* & 5.81 & 4.93 & 20.25 & 12.77 & 0.000 \\
\hline STAI-S* & 37.8 & 8.14 & 56.42 & 9.96 & 0.000 \\
\hline STAI-T* & 39.2 & 8.67 & 55.00 & 11.58 & 0.000 \\
\hline
\end{tabular}

Normal: temporarily maladjusted subjects: evaluated as normal in the psychiatric evaluation within military maladjusted group. ${ }^{*} \mathrm{p}<0.05$, ${ }^{* *} \mathrm{p}<0.001$. EDMT: Ewha Defense Mechanism Test, BDI: Beck Depression Inventory, STAI: State-Trait Anxiety Inventory 
the control group did (Table 3).

\section{DISCUSSION}

Overall, the maladjusted groups used immature defense systems and the control group used mature defense systems. The temporarily maladjusted group more frequently used somatization, regression, and evasion than did the control group. As above, there was a difference in the pattern of defense mechanisms according to adaptive ability, but there was no difference according to their psychiatric diagnosis. Thus the defense mechanisms may be more useful than the diagnosis of mental illness in predicting successful adaptation. The subjects recruited during the routine examination in the MMA also showed specific immature defense mechanisms like the other groups. In addition to experiencing difficulties with actual adaptation, even with anticipatory anxiety, they experienced sufficient psychological discomfort, which can be a risk of failure of adaptation.

After enlistment, the group that complained about difficulties in adjustment at the training camp was the first to experience psychological difficulties that were not previously seen. They also consistently used immature defenses. We compared sequential and multidisciplinary adaptations to the situation of military service, whereas previous studies had been directed at soldiers deployed to their units, ${ }^{11,17,18}$ and achieved similar results at each stage. Vaillant classified the defense mechanisms into four stages; narcissistic, immature, neurotic, and mature. Uses of mature defense mechanisms by the control group were similar to previous findings. ${ }^{19,20}$

Specific differences were that the control group used distortion, identification, control, and rationalization more than the maladjusted group. Distortion is classified as narcissistic, identification is immature, and control and rationalization are classified as neurotic defenses. Control and distortion were categorized as one of the mature defense systems as an egoexpanding response in the factor analysis of EDMT; so a higher frequency of usage would be appropriate as a mature ego function. If one excessively uses control defense, to avoid necessary emotional response, it would be a neurotic defensive mechanism, but the proper level of control ability can be seen as the function of the ego to suppress impulsivity in response to external stress. Distortion can also be seen as an ego-function to protect the core of narcissism as a form of 'cognitive disharmony' in order to adapt to the situation in reality, not to the level of arbitrary distortion of reality. Good rationalization reflects the ability to adapt standards to the given conditions in order to adapt to the environment, even if it is different from the subject's own standards. It also reflects cognitive flexibility. These defenses would be valuable in situations such as military service for young adults. Identification and rationalization were also not mature defenses. We assumed that these defenses were used as tools to adapt to the military system, which was not looked at as rational for the civilians or new recruits. The army has to adapt them as quickly as possible and encourage them to identify with seniors. Therefore, identification would be useful and easy to use. Several defenses generally classified as immature, neurotic, and narcissistic mechanisms were used more frequently by the control group, which suggests that these defenses would helpful for young adults in their early twenties in adapting to mandatory military service, which would be experienced as a strange and stressful situation.

Post-enlistment subjects (Gr 2 \& 3) used anticipation less frequently than did the control group or the pre-enlistment subjects ( $\mathrm{Gr} 1)$. Anticipation was used to prepare for the near future. The post-enlistment group might no longer need anticipation as a defense mechanism. The control group used anticipation for appropriate preparation, and pre-enlistment subjects used anticipation as reaction to excessive tension and anxiety by the result. There was no difference in defense mechanisms in terms of psychiatric diagnosis. In contrast, defense mechanisms are a variation of spectrum systems among normal population and could therefore be more useful to detect the ability to adapt to a specific stressful situation, which might suggest that evaluation of defense mechanisms would be more related to adaptation ability in a stressful situation, such as military service, than is the severity or presence of mental illness.

The temporarily maladjusted group was originally normal but experienced temporary severe stress. They had enough resilience and mostly normal functioning in everyday life, but that could not be verified by current psychiatric evaluation focused on psychopathology. In this study, we found that they used patterns of defense mechanism different from those of the control group. They used somatization, regression, and evasion, which might suggest that subjects in their early twenties in specific stressful situations would show somatic symptoms of regressive behavior for short period, but these were not early symptoms of specific mental illness. Those immature defenses would indicate the risk factors of possible transient mental discomforts.

This study has provided useful information not only to apply to the special situation of mandatory military service in Korea, but also to find out what defenses are needed to adapt well to the stressful situations that can be encountered in early adulthood.

The strength of this study is that subjects were of the same gender and age group with the same stressful experience. We also evaluated the subjects sequentially, following the stages of military service, so we could assume the specific problems 
during each stage.

The limitations of the study were that we could not enroll females; so it cannot be extended to both genders. The test and control groups were not equal in size and were relatively small. Despite these limitations, this study has significance in that it evaluated the defense systems for the first time in terms of military-service maladjustment.

\section{Conflicts of Interest}

The authors have no potential conflicts of interest to disclose.

\section{Author Contributions}

Conceptualization: Jee Hyun Ha. Data curation: Ji-Won Nam, Eunkyung Choi. Formal analysis: Doo-Heum Park. Investigation: Ji-Won Nam, Eunkyung Choi. Methodology: Ji-Won Nam, Eunkyung Choi. Project administration: Jee Hyun Ha, Seung-Ho Ryu. Resources: Seung-Ho Ryu. Software: Ji-Won Nam, Doo-Heum Park. Supervision: Jee Hyun Ha. Validation: Jee Hyun Ha. Visualization: Ji-Won Nam. Writing_original draft: Ji-Won Nam. Writing_review \& editing: Jee Hyun Ha.

\section{ORCID iDs}

Jee Hyun Ha https://orcid.org/0000-0002-0973-1139

Ji-Won Nam https://orcid.org/0000-0002-2085-9571

\section{REFERENCES}

1. Association AP. Diagnostic and Statistical Manual of Mental Disorders, Fourth Edition. Washington, DC: American Psychiatric Association; 1994.

2. Freud S. The Neuro-Psychoses of Defense. London: Karnac book; 1894.

3. Freud A. The Ego and the Mechanisms of Defence. New York: International Universities Press; 1946.

4. Vaillant GE. Theoretical hierarchy of adaptive ego mechanisms: a 30year follow-up of 30 men selected for psychological health. Arch Gen Psychiatry 1971;24:107-118.

5. Vaillant GE. Ego mechanisms of defense and personality psychopathology. J Abnorm Psychol 1994;103:44-50.
6. Bond M. Empirical studies of defense style: relationships with psychopathology and change. Harv Rev Psychiatry 2004;12:263-278.

7. Paek M. Anger and Aggression during Military Service. Seongnam: 2015 Military psychiatric conference; 2015.

8. Service NAR. 2014 Parliamentary Inspection of the Administration. Seoul: National Assembly Research Service; 2014.

9. Jones E, Hyams KC, Wessely S. Screening for vulnerability to psychological disorders in the military: an historical survey. J Med Screen 2003; 10:40-46.

10. Choi K, Im H, Kim J, Choi KH, Jon DI, Hong H, et al. Relationship of early-life stress and resilience to military adjustment in a young adulthood population. Soc Psychiatry Psychiatr Epidemiol 2013;48:17671776.

11. Jang SG, Lee SK, Choi JH. Control study on temperament and character traits, resilience, and predictors of military maladjusted soldiers. J Korean Neuropsychiatr Assoc 2014;53:178-185.

12. Rhee KH, Kim JU, Kim JK, Park YS. A standardization study of EWHA defense mechanism test. J Korean Neuropsychiatr Assoc 1991;30:582592.

13. Kim J, Rhee K, Kim J, Park Y. Ewha Diagnostic Test of Defense Mechanism. Seoul: Hana Medical Publishing Company; 1991.

14. Beck AT, Ward CH, Mendelson M, Mock J, Erbaugh J. An inventory for measuring depression. Arch Gen Psychiatry 1961;4:561-571.

15. Han HM, Yeom TH, Shin YW, Kim KH, Yoon DJ, Chung KH. The validity and reliability of Beck Depression Inventory Korean version. J Korean Neuropsychiatr Assoc 1986;25:487-500.

16. Spielberger CD, Gorsuch RL, Lushene PR, Vagg PR, Jacobs GA. Manual for the State-Trait Anxiety Inventory. Palo Alto, CA: Consulting Psychologists Press, Inc; 1983.

17. Na KS, Oh SJ, Jung HY, Lee SI, Kim YK, Han C, et al. Temperament and character of young male conscripts with adjustment disorder: a casecontrol study. J Nerv Ment Dis 2012;200:973-977.

18. Han KH, Lee SB. The temperament and character of Korean male conscripts with military maladjustment- a preliminary study. Psychiatry Investig 2013;10:131-136.

19. Dedic G. Defense mechanisms in soldiers during the period of adaptation to the military environment. Vojnosanit Pregl 2000;57:393-401.

20. Doruk A, Sütçigil L, Erdem M, Işıntaş M, Özgen F. Defense mechanisms in adjustment disorder. Yeni Symposium 2009;47:135-141. 